\title{
Primary Lung Cancer After Treatment for Breast Cancer
}

\section{Qian Long* \\ Yan Wang (1)* \\ Guowei Che $\mathbb{D}$}

Department of Thoracic Surgery, West China Hospital, Sichuan University, Chengdu, Sichuan Province, People's Republic of China

*These authors contributed equally to this work
Correspondence: Guowei Che Department of Thoracic Surgery, West China Hospital, Sichuan University, Chengdu, Sichuan Province, People's Republic of China

Email cheguoweixw@126.com

\begin{abstract}
Breast cancer is the most common malignancy in women and the second most common cause of cancer-related death. Due to advances in the diagnosis and treatment technologies for breast cancer, patients with breast cancer are living longer than before, resulting in an increased risk of developing subsequent malignancies, among which lung cancer is the most common. This review presents the current evidence about the risk, influencing factors and prognostic factors of developing primary lung cancer after treatment for breast cancer. The aim is to help clinicians improve their understanding, diagnosis and treatment of lung cancer after breast cancer.
\end{abstract}

Keywords: second lung cancer, breast cancer, review

\section{Introduction}

In the past 20 years, we have made great progress in the early diagnosis, surgical therapy and chemoradiotherapy of breast cancer. Therefore, the prognosis of patients with breast cancer has been significantly improved with a much longer survival period. Due to the prolonged survival time of patients, the long-term complications of antitumor treatment have gradually become prominent. It has been widely reported that some antitumor therapy measures, such as radiotherapy, also increase the risk of second primary malignancies. ${ }^{1-3}$ In a study enrolling more than 500,000 breast cancer patients, they were significantly more likely to develop a second primary tumor than the general population. Meanwhile, this phenomenon became more obvious as their survival time increased. Patients who lived longer than 10 years showed a forty percent increased risk of the occurrence of other tumors, such as lung cancer, esophageal cancer and soft tissue sarcoma. In particular, the incidence of soft tissue sarcomas in the chest and upper limbs increased ten-fold (Table 1). ${ }^{4}$

Breast cancer is the most common malignant tumor in women and the second leading cause of cancer-related deaths. ${ }^{5}$ Most patients receive adjuvant therapies such as chemotherapy and endocrine therapy after surgery, and these treatments have a certain effect on the occurrence of subsequent primary tumors. ${ }^{6}$ A considerable number of breast cancer patients will receive chest CT examinations during follow-up, so they have a higher chance of discovering pulmonary diseases such as lung cancer than the general population, especially breast cancer patients with lymph node metastases. In addition, previous studies indicated that some other parameters, such as smoking, age and disease stage of breast cancer, may affect the risk of second primary lung cancer in breast cancer patients. ${ }^{2,7-10}$ Meanwhile, the prognosis of this group of patients might be affected by the disease stage of the lung cancer, histological grade and age. ${ }^{9}$ 
Table I Standard Incidence Ratios and 95\% Confidence Intervals for Subsequent Primary Tumor in Breast Cancer Patients Who Lived Longer Than 10 Years

\begin{tabular}{|l|l|l|}
\hline Second Primary Cancer Sites & $\begin{array}{l}\text { Standard } \\
\text { Incidence } \\
\text { Ratio }\end{array}$ & $\begin{array}{l}\text { 95\% } \\
\text { Confidence } \\
\text { Interval }\end{array}$ \\
\hline All sites & 1.42 & $1.39-1.44$ \\
Soft tissue sarcoma* & 10.75 & $8.16-13.89$ \\
Bone & 2.66 & $1.73-3.89$ \\
Myeloid leukaemia & 2.11 & $1.78-2.49$ \\
Esophagus & 2.09 & $1.80-2.42$ \\
Thyroid gland & 1.86 & $1.57-2.19$ \\
Skin cancer except for melanoma & 1.77 & $1.67-1.87$ \\
Ovary & 1.75 & $1.63-1.88$ \\
Lung & 1.68 & $1.59-1.78$ \\
Stomach & 1.49 & $1.38-1.62$ \\
Leukemia & 1.43 & $1.28-1.60$ \\
Corpus uteri & 1.40 & $1.30-1.50$ \\
Oral cavity and pharynx & 1.40 & $1.21-1.61$ \\
Melanoma & 1.39 & $1.25-1.54$ \\
Non-Hodgkin's lymphoma & 1.39 & $1.26-1.54$ \\
Pancreas & 1.32 & $1.20-1.44$ \\
Colorectal & 1.30 & $1.24-1.36$ \\
Bladder & 1.30 & $1.17-1.45$ \\
Kidney & 1.27 & $1.14-1.42$ \\
\hline Nots & & \\
\hline
\end{tabular}

Notes: *Soft tissue sarcoma of the upper limbs and chest including the shoulders. Reproduced wih permission from Mellemkjaer L, Friis S, Olsen JH, et al. Risk of second cancer among women with breast cancer. Int J Cancer.. 2005; I I8(9):22852292. Copyright (c) 2005 Wiley-Liss, Inc. ${ }^{4}$

Thus, this article presented current evidence of the risk and influencing factors of lung cancer in breast cancer patients and the prognostic risk factors for such patients to enhance the awareness and understanding of clinicians about subsequent lung cancer in breast cancer and improve the diagnosis, treatment and management of this group of patients.

\section{The Risk of Subsequent Lung Cancer in Breast Cancer Patients}

During the past 20 years, an increasing number of studies have explored the difference in the risk of lung cancer between breast cancer patients and the general population. After systematically searching for relevant literature, we selected some high-quality studies and have presented them in Table 2.

Mellemakjar et al collected 525,527 breast cancer patients and analyzed the occurrence of second primary tumors and compared this data with the incidence of lung cancer as the first primary cancer in the general population. The participants were from 13 national oncology registries, including New South Wales in Australia, Zaragoza in Spain, British Columbia, Denmark, Finland, Iceland, Manitoba and Saskatchewan in Canada, Slovenia, Sweden, Norway, Scotland and Singapore. ${ }^{4}$ The patients were divided into different groups according to the interval between the diagnosis of breast cancer and the diagnosis of lung cancer. Their results indicated that the risk of lung cancer in breast cancer patients was not significantly higher than that in the general population within one year after the diagnosis of breast cancer [standard incidence ratio $(\mathrm{SIR})=0.93,95 \%$ confidence interval (CI): 0.81-1.05]. However, the risk of subsequent lung cancer increased after one year $(1-9$ years: $\mathrm{SIR}=1.08$, 95\% CI: $1.02-1.13$; $10+$ years: $\mathrm{SIR}=1.68,95 \%$ CI: 1.59-1.78). When the patients were divided into different groups according to their age at the diagnosis of breast cancer $(\leq 45,46-55$ and $\geq 56)$, female breast cancer patients in any subgroup showed a significantly higher risk of developing lung cancer than women from the general population in the same age group. Notably, when the patients were grouped by time (before 1975, 1975-1983, 1984-1990 and after 1991), the increased risk of lung cancer weakened over time, with SIRs of $1.64,1.23,1.10$, and 0.98 , respectively. ${ }^{4}$ The authors considered that this phenomenon might be related to the continuous improvement of radiotherapy technology, which was manifested by the gradual reduction of radiation exposure to normal pulmonary tissues.

Utada et al included and analyzed the data of 174,477 cancer patients from the Nagasaki Prefecture Cancer Registry of Japan. Compared to the incidence of lung cancer as the first primary tumor, the risk for subsequent lung cancer in female breast cancer patients increased by approximately $40 \%$ (SIR=1.41, 95\% CI: $1.13-1.73) .{ }^{11}$ Another similar study conducted by Evans et al was based on the Thames Cancer Registry, which collected tumor-related data of residents in southeastern England involving a population of 14 million. They enrolled 112,878 cases and found that the risk of subsequent lung cancer in female breast cancer patients increased by approximately $60 \%$ compared with the general population ( $\mathrm{SIR}=1.60,95 \%$ CI: 1.23-2.09, $\mathrm{P}<0.001) .{ }^{12}$ Schaapveld et al drew a similar conclusion by analyzing 58,068 cases, and female breast cancer patients were found to have a much higher risk of second primary lung cancer $(\mathrm{SIR}=1.22,95 \% \mathrm{CI}: 1.08-1.36) .{ }^{13}$ 
Table 2 Relevant Literatures About the Risk of Subsequent Primary Lung Cancer After Breast Cancer

\begin{tabular}{|c|c|c|c|c|c|c|c|}
\hline Author & $\begin{array}{l}\text { Publication } \\
\text { Year }\end{array}$ & Database/Region & Period & $\begin{array}{l}\text { Sample } \\
\text { Size }\end{array}$ & $\begin{array}{l}\text { Follow-Up } \\
\text { (Year) }\end{array}$ & SIR & $95 \% \mathrm{Cl}$ \\
\hline Dorffel $^{14}$ & 2000 & GDR/German & $1976-1988$ & 5485 & - & 1.65 & $0.93-2.73$ \\
\hline Rubino ${ }^{15}$ & 2000 & IGR/France & $1973-1992$ & 4416 & $0-10+$ & 1.0 & $0.4-2.1$ \\
\hline Evans $^{12}$ & 2001 & South east of England & $1961-1995$ & 145,677 & $0-15+$ & 1.60 & $1.23-2.09$ \\
\hline Levi $^{16}$ & 2003 & Switzerland & $1974-1998$ & 9729 & $0-5+$ & 1.04 & $0.72-1.46$ \\
\hline Mellemkjaer ${ }^{4}$ & 2006 & $\begin{array}{l}\text { International Oncology } \\
\text { Database }\end{array}$ & $1943-2000$ & 525,527 & $0-10+$ & 1.50 & $1.01-2.23$ \\
\hline Lee $^{17}$ & 2008 & TNCR/Taiwan, China & 1979-2003 & 53,783 & $0-10+$ & 1.27 & $0.57-2.84$ \\
\hline Schaapveld ${ }^{13}$ & 2008 & Netherlands & 1989-2003 & 58,068 & $0-15+$ & 1.22 & $1.08-1.36$ \\
\hline Rosso $^{18}$ & 2009 & PCR/ltaly & $1985-2003$ & 9233 & - & 0.80 & $0.54-1.15$ \\
\hline$Y^{19}$ & 2013 & ACC/USA & 1979-2007 & 4198 & $2-30.5$ & 1.84 & $1.25-2.42$ \\
\hline Utata ${ }^{\prime \prime}$ & 2014 & NPCR/Japn & $1985-2007$ & 174,477 & - & 1.41 & $1.13-1.73$ \\
\hline Hamilton ${ }^{20}$ & 2015 & Canada & $1989-2005$ & 12,836 & $0-10+$ & 1.08 & $0.91-1.27$ \\
\hline Bazire $^{2 !}$ & 2017 & Paris, France & $198 \mid-2000$ & 17,745 & $2-29$ & 1.39 & $1.13-1.72$ \\
\hline Silverman ${ }^{22}$ & 2017 & INCR/Israel & $1990-2006$ & 46,090 & - & 1.22 & $1.08-1.35$ \\
\hline $\operatorname{Lin}^{23}$ & 2018 & $\begin{array}{l}\text { TNHI and TNCR/Taiwan, } \\
\text { China }\end{array}$ & 2000-20II & 88,446 & $0-3+$ & $\begin{array}{l}1.32 / \\
1.25\end{array}$ & $\begin{array}{l}0.81-2.16 / 0.66- \\
2.36\end{array}$ \\
\hline Wang $^{9}$ & 2018 & SEER/USA & $2000-2014$ & 6269 & $0-10+$ & 1.03 & $1.00-1.06$ \\
\hline
\end{tabular}

Abbreviations: GDR, German Democratic Republic; IGR, Institute Gustave Roussy; TNCR, Taiwan National Cancer Registry; PCR, Piedmont Cancer Registry; ACC, Anderson Cancer Center; NPCR, Nagasaki Prefecture Cancer Registry; INCR, Israel National Cancer Registry; TNHI, Taiwan National Health Insurance; SEER, Surveillance, Epidemiology and End Results; DBCG, Danish Breast Cancer Cooperative; SIR, Standard incidence ratio; Cl, confidence interval; -, not reported.

Based on the above studies, it is relatively credible that breast cancer patients are more likely to develop lung cancer than the general population.

\section{Factors Influencing the Risk of Subsequent Lung Cancer in Breast Cancer Patients Age at the Diagnosis of Breast Cancer}

The incidence of breast cancer in women rises sharply after 25 years old, reaches a peak between 50 and 54 years old and then declines gradually. Afterward, a small peak of morbidity would appear between 60 and 64 years old and then decline rapidly. More than $80 \%$ of breast cancer patients are diagnosed at an age between 30 and 60 years old, and current evidence indicates that breast cancer patients tend to be younger than previously. ${ }^{14,15} \mathrm{On}$ the other hand, lung cancer is also more common in middle-aged and elderly people, and more than $85 \%$ of patients are over 45 years old. ${ }^{16}$ A case-control study performed by Ford et al demonstrated that breast cancer patients younger than 50 years old were more likely to develop subsequent lung cancer than patients older than 50 [odds ratio $(\mathrm{OR})=1.51,95 \% \mathrm{CI}$ : $1.07-2.14, \mathrm{P}=0.048$. $^{7}$ There are some possible causes for this phenomenon: 1) younger patients may be followed up for a longer period; 2) it is a retrospective case-control study with a small sample size (280 participants in the case group and 300 participants in the control group); and 3) overall, the incidence of lung cancer in people over the age of 50 years old is higher than that in people under 50; meanwhile, lung cancer patients also tend to be younger than before. $^{18,19}$

However, some other studies reported opposite findings. ${ }^{2,9,20-22}$ Wang et al retrospectively analyzed the occurrence of second primary lung cancer in 620,429 female breast cancer cases. Although this article revealed a trend that the risk of subsequent lung cancer gradually 
decreased with age, we found that female breast cancer patients over 50 years old were more likely to develop lung cancer than patients under 50 [relative risk (RR) $=4.408$, 95\% CI: 3.998-4.860]. This meant that age $>50$ was a risk factor for second primary lung cancer in breast cancer patients. ${ }^{9}$ Huang et al performed a randomized controlled trial (RCT) and included 7408 female breast cancer patients (3400 patients with age $<50$ and 4008 patients with age $\geq 50$ ). Forty-four and 88 subsequent lung cancer cases occurred in the younger and older groups, respectively. The results also indicated that patients aged $\geq 50$ years were more likely to develop lung cancer (RR=1.697, 95\% CI: 1.185-2.429). ${ }^{2}$

Therefore, based on current studies, we speculated that the age at breast cancer diagnosis might be a risk factor for lung cancer after breast cancer. However, additional highquality studies are necessary to test this conjecture.

\section{Smoking}

The association of smoking with pulmonary tumors has been widely verified. O'Keeffe et al conducted a systematic review and meta-analysis by including 99 cohort studies involving seven million participants and found that smoking increased the risk of lung cancer in women by seven times ( $\mathrm{RR}=6.99,95 \% \mathrm{CI}$ : 5.09-9.59). ${ }^{24}$ A case-control study by Ford et al demonstrated that the incidence of lung cancer in breast cancer patients with a history of smoking was significantly higher than that in breast cancer patients without a smoking history (OR=9.08, 95\% CI: 5.97-13.81, $\mathrm{P}<0.001){ }^{7}$ Similarly, another case-control study by Kaufman et al also showed that the incidence of lung cancer in smoking patients with breast cancer was much higher than that in nonsmoking patients $(\mathrm{OR}=11.44,95 \% \mathrm{CI}: \quad 6.05-21.65, \mathrm{P}<0.001) .{ }^{8}$ Thus, smoking should be a high-risk factor for subsequent primary lung cancer after treatment for breast cancer, but additional studies with larger samples are necessary to confirm this hypothesis.

\section{Tumor Stage of Breast Cancer}

Liu et al retrospectively reviewed 535,941 female breast cancer cases from the Surveillance, Epidemiology and End Results (SEER) database and found that advanced tumornode-metastasis (TNM) stage was a protective factor for lung cancer after breast cancer (RR $=0.88,95 \%$ CI: $0.81-0.94),{ }^{10}$ which was similar to the results reported by Ford et al $(\mathrm{RR}=0.39,95 \%$ CI: $0.22-0.68) .{ }^{7}$ Liu et al also explored the relationship of the risk of lung cancer with T, N and M stage.
In detail, patients with advanced $\mathrm{T}$ stage $(\mathrm{T} 3 / 4)(\mathrm{RR}=0.801$, 95\% CI: $0.718-0.894)$, lymph node metastasis ( $\mathrm{RR}=0.802$, 95\% CI: $0.760-0.847)$ or distant metastasis ( $\mathrm{RR}=0.790,95 \%$ CI: $0.637-0.979)$ showed a lower risk for second primary lung cancer. ${ }^{10}$

We consider that the above findings to be rational. Patients with advanced tumor stages have shorter survival times, resulting in a decreased risk for a second malignancy.

\section{Radiotherapy}

To date, a number of studies have explored the relationship between radiotherapy and the occurrence of lung cancer. It has been reported that radiotherapy inevitably causes DNA damage to normal tissue cells, and this kind of DNA damage persists due to splicing mutations and abnormal regulation of TP53, a tumor suppressor gene. This could cause tumorigenesis through a special pathway. ${ }^{25,26}$ The relevant literature investigating the association between radiotherapy for breast cancer and the occurrence of subsequent lung cancer is shown in Table 3.

In the study by Huang et al, among the 5685 patients who received radiotherapy, second primary lung cancer occurred in 128 cases $(2.25 \%)$, and only 4 lung cancer cases occurred in the nonradiotherapy group involving 1713 patients. The results indicated a significant relationship between radiotherapy and subsequent primary lung cancer (RR=9.62, 95\% CI: 3.56-26.00, $\mathrm{P}<0.001) .{ }^{2}$ Before this study, Deutsch et al conducted two other RCTs for similar exploration. However, the results of these trials were inconsistent. ${ }^{30}$ In the NSABP B-04 trial, 38.8\% $(646 / 1,665)$ of patients received radiotherapy, and 14 $(2.17 \%)$ and $9(0.88 \%)$ subsequent lung cancer cases occurred in the radiotherapy group and nonradiotherapy group, respectively. These results indicated that radiotherapy was a risk factor for lung cancer after breast cancer $(\mathrm{RR}=2.45,95 \% \mathrm{CI}: 1.07-5.64)$. However, in another trial named NSABP B-06, the incidence of lung cancer in the radiotherapy group and nonradiotherapy group were $1.43 \%(9 / 628)$ and $1.72 \%(21 / 1222)$, respectively, which indicated a nonsignificant association between radiotherapy and the occurrence of lung cancer $(\mathrm{RR}=0.85,95 \% \mathrm{CI}$ : 0.39-1.84). Andersson et al retrospectively analyzed the occurrence of second primary malignancies in 31,818 female breast cancer patients, and the results demonstrated that radiotherapy was significantly related to the risk of lung cancer after breast cancer $(\mathrm{RR}=1.33,95 \% \mathrm{CI}$ : 1.00 $1.77, \mathrm{P}=0.05){ }^{33}$ 
Table 3 Relevant Literatures About the Association Between Radiotherapy for Breast Cancer and Risk for Subsequent Lung Cancer

\begin{tabular}{|c|c|c|c|c|c|c|c|}
\hline Author & Publication Year & Database/Region & Period & Type of Study & Sample Size & RR/OR & $95 \% \mathrm{Cl}$ \\
\hline Neugut $^{27}$ & 1994 & CTR/USA & - & CCS & 1164 & 2.80 & $1.20-6.40$ \\
\hline Obedian $^{28}$ & 2000 & YNHS/ USA & $1970-1990$ & CS & 2416 & 0.73 & $0.29-1.81$ \\
\hline Zablotska $^{29}$ & 2003 & SEER/ USA & $1973-1998$ & CS & |9498| & 1.09 & $0.97-1.22$ \\
\hline Zablotska $^{29}$ & 2003 & SEER/ USA & $1980-1998$ & $\mathrm{CS}$ & 65560 & 1.40 & $1.11-1.75$ \\
\hline Ford ${ }^{7}$ & 2003 & ACC/ USA & $1960-1997$ & CCS & 580 & 1.03 & $0.74-1.43$ \\
\hline Deutsch ${ }^{30}$ & 2003 & Pittsburgh, USA & $197 \mid-1974$ & RCT & 1665 & 2.45 & $1.07-5.64$ \\
\hline Deutsch $^{30}$ & 2003 & Pittsburgh in USA & $1976-1984$ & RCT & 1850 & 0.85 & $0.39-1.84$ \\
\hline Roychoudhuri $^{31}$ & 2004 & TCR/South east of England & $|96|-2000$ & CS & 64782 & 1.10 & $0.92-1.31$ \\
\hline $\operatorname{Levi}^{32}$ & 2006 & SVCR/Switzerland & $1978-1998$ & CS & 6119 & 1.91 & $0.90-4.07$ \\
\hline Schaapveld ${ }^{13}$ & 2008 & Netherlands & 1989-2003 & CS & 14678 & 2.31 & $1.15-4.60$ \\
\hline Schaapveld ${ }^{13}$ & 2008 & Netherlands & 1989-2003 & CS & 43390 & 0.94 & $0.72-1.22$ \\
\hline Andersson ${ }^{33}$ & 2008 & DBCG/Denmark & $|977-200|$ & CS & 31818 & 1.33 & $1.00-1.77$ \\
\hline Bazire $^{21}$ & 2017 & Paris, France & $198 \mid-2000$ & CS & 17745 & 2.11 & $0.97-4.60$ \\
\hline Huang $^{2}$ & 2017 & LHID/Taiwan, China & $2000-2010$ & RCT & 7408 & 9.62 & $3.56-26.00$ \\
\hline Withrow ${ }^{3}$ & 2017 & SEER/USA & $1992-2008$ & CS & 52556 & 1.33 & $1.10-1.60$ \\
\hline DiMarzio' & 2018 & New York, USA & $2000-2014$ & CS & 3918 & 4.98 & $2.06-12.05$ \\
\hline DiMarzio' & 2018 & New York, USA & $2000-2014$ & CS & 6218 & 1.59 & $0.59-4.32$ \\
\hline
\end{tabular}

Abbreviations: CTR, Connecticut Tumor Registry; YNHH, Yale New Haven Hospital; TCR, Thames Cancer Registry; SEER, Surveillance, Epidemiology and End Results; ACC, Anderson Cancer Center; SVCR, Swiss Vaud Cancer Registry; DBCG, Danish Breast Cancer Cooperative Group; LHID, Longitudinal Health Insurance Database; $\mathrm{CCS}$, case-control study; CS, cohort study; RCT, randomized controlled study; RR, relative risk; OR, odds ratio; Cl, confidence interval; -, not reported.

Meanwhile, in the studies by Deutsch et al and Zablotska et $\mathrm{al}^{29,30}$ they distinguished the relative position (ipsilateral and contralateral) of the breast tumor and pulmonary tumor lesions. The incidence of ipsilateral lung cancer in the NSABP B-04 trial was $1.39 \%$ in the radiotherapy group and $0.29 \%$ in the nonradiotherapy group, and in the NSABP B-06 trial, the incidences were $0.32 \%$ and $0.41 \%$, respectively. A significant difference was only observed in the B-04 trial. ${ }^{30}$ Zablotska et al reported that the incidences of ipsilateral lung cancer in the radiotherapy and nonradiotherapy groups were $0.67 \%$ and $0.54 \%$ among patients undergoing mastectomy, indicating a significant association. The incidence of ipsilateral lung cancer in the radiotherapy and nonradiotherapy groups among patients receiving lumpectomy were $0.37 \%$ and $0.29 \%$, respectively, a nonsignificant association. For contralateral lung cancer cases, a significant difference was only observed among patients receiving lumpectomy $(0.39 \%$ vs $0.27 \%){ }^{29}$

Based on the current evidence, it is believed that radiotherapy for breast cancer plays a considerable role in the development of subsequent primary lung cancer. However, more RCTs are necessary to verify this.

On the other hand, previous studies revealed that the damage to normal pulmonary tissues by radiotherapy could be affected by many factors, such as the radiation source, treatment strategy, technique, dose, radiation field size and segmentation. With the continuous development and advancement of radiotherapy technology, the incidence of adverse events caused by radiotherapy, especially radiation lung injury, has decreased dramatically in recent years. Therefore, we believe that the impact of radiotherapy on subsequent lung cancer would be less in the future.

\section{Chemotherapy}

Chemotherapy is often applied as an adjuvant treatment in breast cancer patients. Meanwhile, with the development of neoadjuvant chemotherapy in recent years, a considerable number of breast cancer patients receive chemotherapy as an antitumor treatment. In the study by Zhong et al, $41 \%$ of breast cancer patients $(260,797 /$ $629,976)$ received chemotherapy, among which 2040 patients developed lung cancer $(0.78 \%)$. Among the other 369,180 patients without a history of chemotherapy, 4553 subsequent lung cancer cases (1.23\%) were observed. These results showed that the risk of lung cancer in the chemotherapy group was much lower than that in the nonchemotherapy group ( $\mathrm{RR}=0.63,95 \% \mathrm{CI}: 0.60$ 0.67). ${ }^{34}$ Additionally, in the study by Li et al, approximately half of patients received chemotherapy $(120,333 /$ $250,764)$, and the risk of lung cancer in the chemotherapy group was significantly lower than that in the 
nonchemotherapy group $(\mathrm{RR}=0.895,95 \%$ CI: $0.818-$ $0.979, \mathrm{P}=0.015),{ }^{35}$ which was consistent with the findings reported by previous studies. ${ }^{7}$ We considered that this phenomenon might be related to the therapeutic effects of some chemotherapeutic agents for breast cancer, such as docetaxel, paclitaxel and gemcitabine, on lung cancer. $^{36,37}$

\section{Estrogen Receptor (ER), Progesterone Receptor (PR) and Human Epidermal Growth Factor Receptor-2 (HER-2)}

The expression of the ER, PR and HER-2 genes in breast cancer is related to the prognosis and therapeutic strategies of the patients. Patients with negative ER, PR or HER-2 expression usually have a worse prognosis than patients with positive ER, PR or HER-2 expression. ${ }^{38-40}$ On the other hand, patients with positive ER or PR and HER-2 genes are candidates for endocrine and anti-HER-2 targeted therapies, respectively. In the study by Liu et al, ${ }^{10}$ $79.8 \%(362,825 / 454,791), 69.5 \%(311,513 / 447,917)$ and $15.9 \%(22,321 / 140,742)$ of patients had positive ER, PR and HER-2 gene expression. The incidence of subsequent lung cancer was $1.29 \%, 1.24 \%$ and $0.17 \%$ in patients with positive ER, PR and HER-2, respectively, and the incidence of lung cancer was $1.39 \%, 1.44 \%$ and $0.23 \%$ in patients with negative ER, PR and HER-2, respectively. After further calculation, we found that the expression status of ER and PR was significantly related to the risk of subsequent lung cancer after breast cancer (ER: $\mathrm{RR}=0.93,95 \%$ CI: $0.87-0.99, \mathrm{P}=0.014$; PR: $\mathrm{RR}=0.86$, 95\% CI: $0.82-0.91, \mathrm{P}<0.001)$. Specifically, patients with negative ER or PR were more likely to develop lung cancer than patients with positive ER or PR. Nevertheless, there was no significant association between the expression of the HER-2 gene and second primary lung cancer $(\mathrm{RR}=0.72,95 \% \mathrm{CI}$ : 0.51-1.01, $\mathrm{P}=0.055)$.

After reviewing the previous literature, we found that the expression of the ER, PR and HER-2 genes was also related to the occurrence, development and prognosis of pulmonary tumors. ${ }^{41-44}$ ER and PR might impact the expression pathways of the epidermal growth factor receptor (EGFR) gene. ${ }^{41,42}$ However, two subtypes of ER (ER $\alpha$ and ER $\beta$ ) showed opposite influences on lung cancer patients. High expression of ER $\alpha$ [hazard ratio $(\mathrm{HR})=1.83,95 \% \mathrm{CI}: 1.31-2.55, \mathrm{P}<0.001$ ] and low expression of $\mathrm{ER} \beta \quad(\mathrm{HR}=1.28,95 \% \mathrm{CI}: 1.03-1.59$, $\mathrm{P}=0.028$ ) were both risk factors for a poor prognosis in lung cancer patients. ${ }^{45}$ Thus, additional studies are required to explore the relationship of these three genes with the risk of lung cancer after breast cancer and the potential mechanisms.

\section{Endocrine Therapy}

At present, whether hormones are one of the risk factors for lung cancer is still controversial. A survey involving more than 60,000 postmenopausal women showed that hormone replacement therapy (HRT) was obviously associated with the incidence of lung cancer and depended on the duration of HRT. ${ }^{46}$ However, another survey focusing on teachers in California showed that HRT had no significant effect on the occurrence of lung cancer. ${ }^{46}$ Otherwise, several case-control studies have demonstrated that HRT and oral contraceptive use could significantly reduce the occurrence of lung cancer and were not affected by other factors, such as smoking. Interestingly, they also found that short-term use of exogenous estrogen showed a protective effect, but long-term continuous use increased the risk of lung cancer. ${ }^{47}$ In the study by Andersson et al, ${ }^{33}$ the incidence of lung cancer in female breast cancer patients with or without the long-term use of tamoxifen as endocrine therapy were $0.87 \%(63 / 7204)$ and $1.06 \%(260 / 24,614)$, respectively, which indicated a nonsignificant relationship between endocrine therapy (tamoxifen) and the risk of subsequent lung cancer after breast cancer $(\mathrm{RR}=0.83,95 \%$ CI: $0.63-1.09, \mathrm{P}=0.176)$.

\section{Follow-Up Period}

Several large studies have revealed that the risk of lung cancer increases as the survival time of breast cancer patients increases. ${ }^{4,22}$ The SIRs of second primary lung cancer within 1 year, $1-9$ years, $10-19$ years and $\geq 20$ years after the diagnosis of breast cancer were $0.93,1.08,1.3$ and 2.9, respectively, presenting an obvious upward trend. $^{4,22}$ The authors speculated that this phenomenon might be related to antitumor treatment for breast cancer. Specifically, the risk of subsequent lung cancer increases year by year due to antitumor treatments, but it may cause a short-term decrease in the risk of lung cancer in the early period after treatment.

\section{Prognostic Risk Factors for Breast Cancer Patients with Subsequent Lung Cancer}

A few studies have explored the prognostic factors of patients with breast cancer and second primary lung cancer with inconsistent findings. Wang et al conducted 
a relevant exploration by analyzing 6269 cases from the SEER databases and demonstrated that the ER $(\mathrm{P}<0.001)$, PR $(\mathrm{P}<0.001)$, histological type of breast cancer $(\mathrm{P}=0.001)$, age at the diagnosis of lung cancer $(\mathrm{P}<0.001)$, interval between the diagnosis of breast cancer and lung cancer $(\mathrm{P}<0.001)$, histological type of lung cancer $(\mathrm{P}<0.001)$, differentiation degree $(\mathrm{P}<0.001)$ and tumor stage of lung cancer $(\mathrm{P}<0.001)$ were significantly associated with prognosis of breast cancer patients with subsequent non-small-cell lung cancer (NSCLC). However, for patients with subsequent small cell lung cancer (SCLC), only the tumor stage $(\mathrm{P}<0.001)$ and age at the diagnosis $(\mathrm{P}<0.001)$ of SCLC were prognostic factors. ${ }^{9}$

Chen et al demonstrated that chemotherapy $(\mathrm{P}=0.021)$, lymphovascular space invasion (LVSI) of pulmonary carcinoma $(\mathrm{P}=0.012)$ and ground-glass opacity (GGO) ratio $<50 \% \quad(\mathrm{P}=0.045)$ were independent prognostic risk factors for this group of patients after reviewing 54 cases. Meanwhile, they also found that chemotherapy for lung cancer $(\mathrm{P}<0.001)$, worse differentiation of lung cancer $(\mathrm{P}=0.012)$, pulmonary tumor $\geq 2 \mathrm{~cm}(\mathrm{P}<0.001)$, LVSI of pulmonary carcinoma $(\mathrm{P}=0.031)$ and $\mathrm{GGO}$ ratio $<50 \%$ $(\mathrm{P}=0.014)$ were risk factors for recurrence. ${ }^{48}$

\section{Summary and Prospects}

The risk of lung cancer in breast cancer patients is significantly higher than that in the general population, and this is obviously related to a number of parameters, such as smoking, radiotherapy and chemotherapy. Meanwhile, the prognosis of this group of patients might be affected by several clinicopathological parameters. However, most of the current relevant studies have only reported some clinical trends or phenomena, and we still know very little about the mechanisms by which these parameters affect the risk of subsequent primary lung cancer after treatment of breast cancer. Therefore, it is expected that additional research will focus on the mechanisms of increased risk for second primary lung cancer after treatment for breast cancer and find some possible methods to reduce the risk of subsequent lung cancer.

\section{Ethical Statement}

The authors are accountable for all aspects of the work in ensuring that questions related to the accuracy or integrity of any part of the work are appropriately investigated and resolved. All procedures performed in studies that involved human participants were in accordance with the ethical standards of the institutional and national research committee and with the 1964 Helsinki Declaration and its later amendments or comparable ethical standards. Written informed consent was not applicable for this type of manuscript.

\section{Author Contributions}

All authors made a significant contribution to the work reported, whether that is in the conception, study design, execution, acquisition of data, analysis and interpretation, or in all these areas; took part in drafting, revising or critically reviewing the article; gave final approval of the version to be published; have agreed on the journal to which the article has been submitted; and agree to be accountable for all aspects of the work.

\section{Funding}

This study was funded by Sichuan Science and Technology Program (grant No. 2020YFS0252).

\section{Disclosure}

The authors have no conflicts of interest to declare.

\section{References}

1. DiMarzio P, Peila R, Dowling O, et al. Smoking and alcohol drinking effect on radiotherapy associated risk of second primary cancer and mortality among breast cancer patients. Cancer Epidemiol. 2018;57::97-103. doi:10.1016/j.canep.2018.10.002

2. Huang YJ, Huang TW, Lin FH, Chung $\mathrm{CH}$, Tsao $\mathrm{CH}$, Chien WC. Radiation therapy for invasive breast cancer increases the risk of second primary lung cancer: a nationwide population-based cohort analysis. J Thoracic Oncol. 2017;12(5):782-790. doi:10.1016/j.jtho.2017.01.021

3. Withrow DR, Morton LM, Curtis RE, Schonfeld SJ, Berrington de González A. Radiotherapy for ductal carcinoma in situ and risk of second non-breast cancers. Breast Cancer Res Treat. 2017;166 (1):299-306. doi:10.1007/s10549-017-4410-6

4. Mellemkjaer L, Friis S, Olsen JH, et al. Risk of second cancer among women with breast cancer. Int J Cancer. 2005;118(9):2285-2292. doi:10.1002/ijc.21651

5. Siegel RL, Miller KD, Jemal A. Cancer statistics, 2020. CA Cancer J Clin. 2020;70(1):7-30. doi:10.3322/caac.21590

6. Lorigan P, Radford J, Howell A, Thatcher N. Lung cancer after treatment for Hodgkin's lymphoma: a systematic review. Lancet Oncol. 2005;6(10):773-779. doi:10.1016/S1470-2045(05)70387-9

7. Ford MB, Sigurdson AJ, Petrulis ES, et al. Effects of smoking and radiotherapy on lung carcinoma in breast carcinoma survivors. Cancer. 2003;98(7):1457-1464. doi:10.1002/cncr.11669

8. Kaufman EL, Jacobson JS, Hershman DL, Desai M, Neugut AI. Effect of breast cancer radiotherapy and cigarette smoking on risk of second primary lung cancer. J Clin Oncol. 2008;26(3):392-398. doi:10.1200/ JCO.2007.13.3033

9. Wang R, Yin Z, Liu L, et al. Second primary lung cancer after breast cancer: a population-based study of 6269 women. Front Oncol. 2018;8:427. doi:10.3389/fonc.2018.00427 
10. Liu J, Hu Z, Feng Y, Zeng S, Zhong M. Problems to affect long-term survival for breast cancer patients: an observational study of subsequent lung/bronchus malignancies. Medicine. 2018;97(39):e12603. doi:10.1097/MD.0000000000012603

11. Utada M, Ohno Y, Hori M, Soda M. Incidence of multiple primary cancers and interval between first and second primary cancers. Cancer Sci. 2014;105(7):890-896. doi:10.1111/cas.12433

12. Evans HS, Lewis CM, Robinson D, Bell CM, Møller H, Hodgson SV. Incidence of multiple primary cancers in a cohort of women diagnosed with breast cancer in southeast England. Br J Cancer. 2001;84 (3):435-440. doi:10.1054/bjoc.2000.1603

13. Schaapveld M, Visser O, Louwman MJ, et al. Risk of new primary nonbreast cancers after breast cancer treatment: a Dutch population-based study. J Clin Oncol. 2008;26(8):1239-1246. doi:10.1200/JCO.2007.11.9081

14. Dörffel WV, Reitzig P, Dörffel Y, Possinger K. [Secondary malignant neoplasms in patients with breast cancer]. Zentralbl Gynakol. 2000;122(8):419-427. doi:10.1055/s-2000-10604

15. Rubino C, de Vathaire F, Diallo I, Shamsaldin A, Lê MG. Increased risk of second cancers following breast cancer: role of the initial treatment. Breast Cancer Res Treat. 2000;61(3):183-195. doi:10.1023/a:1006489918700

16. Levi F, Te VC, Randimbison L, La Vecchia C. Cancer risk in women with previous breast cancer. Ann Oncol. 2003;14(1):71-73. doi:10.1093/annonc/mdg028

17. Lee $\mathrm{KD}$, Chen $\mathrm{SC}$, Chan $\mathrm{CH}$, et al. Increased risk for second primary malignancies in women with breast cancer diagnosed at young age: a population-based study in Taiwan. Cancer Epidemiol Biomarkers Prev. 2008;17(10):2647-2655. doi:10.1158/1055-9965.epi-08-0109

18. Rosso S, Terracini L, Ricceri F, Zanetti R. Multiple primary tumours: incidence estimation in the presence of competing risks. Popul Health Metr. 2009;7:5. doi:10.1186/1478-7954-7-5

19. Yi M, Cormier JN, Xing Y, et al. Other primary malignancies in breast cancer patients treated with breast conserving surgery and radiation therapy. Ann Surg Oncol. 2013;20(5):1514-1521. doi:10.1245/s10434-012-2774-8

20. Hamilton SN, Tyldesley S, Li D, Olson R, McBride M. Second malignancies after adjuvant radiation therapy for early stage breast cancer: is there increased risk with addition of regional radiation to local radiation? Int J Radiat Oncol Biol Phys. 2015;91(5):977-985. doi:10.1016/j.ijrobp.2014.12.051

21. Bazire L, De Rycke Y, Asselain B, Fourquet A, Kirova YM. Risks of second malignancies after breast cancer treatment: Long-term results. Cancer Radiother. 2017;21(1):10-15. doi:10.1016/j.canrad.2016. 07.101

22. Silverman BG, Lipshitz I, Keinan-Boker L. Second Primary Cancers After Primary Breast Cancer Diagnosis in Israeli Women, 1992 to 2006. J Glob Oncol. 2017;3(2):135-142. doi:10.1200/jgo.2016.003 699

23. Lin EP, Lin CH, Yang CY, et al. Population-Based Cohort Study Reveals Distinct Associations Between Female Lung Cancer and Breast Cancer in Taiwan. JCO Clin Cancer Inform. 2018;2:1-14. doi: $10.1200 /$ cci. 18.00065

24. O'Keeffe LM, Taylor G, Huxley RR, Mitchell P, Woodward M, Peters SAE. Smoking as a risk factor for lung cancer in women and men: a systematic review and meta-analysis. BMJ Open. 2018;8(10):e021611. doi:10.1136/bmjopen-2018-021611

25. Stathopoulos GT, Sherrill TP, Cheng DS, et al. Epithelial NF-kappaB activation promotes urethane-induced lung carcinogenesis. Proc Natl Acad Sci U S A. 2007;104(47):18514-18519. doi:10.1073/pnas.070 5316104

26. Campbell JD, Alexandrov A, Kim J, et al. Distinct patterns of somatic genome alterations in lung adenocarcinomas and squamous cell carcinomas. Nat Genet. 2016;48(6):607-616. doi:10.1038/ng.3 564
27. Neugut AI, Murray T, Santos J, et al. Increased risk of lung cancer after breast cancer radiation therapy in cigarette smokers. Cancer. 1994;73(6):1615-1620. doi:10.1002/1097-0142(19940315)73:6<16= (99) $15::$ aid-cncr2820730612>3.0.co;2-6

28. Obedian E, Fischer DB, Haffty BG. Second malignancies after treatment of early-stage breast cancer: lumpectomy and radiation therapy versus mastectomy. J Clin Oncol. 2000;18(12):2406-2412. doi:10.1200/jco.2000.18.12.2406

29. Zablotska LB, Neugut AI. Lung carcinoma after radiation therapy in women treated with lumpectomy or mastectomy for primary breast carcinoma. Cancer. 2003;97(6):1404-1411. doi:10.1002/cncr.11214

30. Deutsch M, Land SR, Begovic M, Wieand HS, Wolmark N, Fisher B. The incidence of lung carcinoma after surgery for breast carcinoma with and without postoperative radiotherapy. Results of National Surgical Adjuvant Breast and Bowel Project (NSABP) clinical trials B-04 and B-06. Cancer. 2003;98(7):1362-1368. doi:10.1002/ cncr.11655

31. Roychoudhuri R, Evans H, Robinson D, Møller H. Radiation-induced malignancies following radiotherapy for breast cancer. $\mathrm{Br} J$ Cancer. 2004;91(5):868-872. doi:10.1038/sj.bjc.6602084

32. Levi F, Randimbison L, Te VC, La Vecchia C. Cancer risk after radiotherapy for breast cancer. Br J Cancer. 2006;95(3):390-392. doi:10.1038/sj.bjc.6603235

33. Andersson M, Jensen MB, Engholm G, Henrik Storm H. Risk of second primary cancer among patients with early operable breast cancer registered or randomised in Danish Breast Cancer cooperative Group (DBCG) protocols of the 77, 82 and 89 programmes during 1977-2001. Acta Oncol. 2008;47(4):755-764. doi:10.1080/ 02841860801978921

34. Zhong M, He X, Lei K. Survival of Patients with First and Metachronous Second Primary Breast Cancer or Lung Cancer Malignancy: Comparisons Using the SEER Database. Adv Ther. 2020;37(5):2236-2245. doi:10.1007/s12325-020-01322-0

35. Li D, Weng S, Zhong C, et al. Risk of Second Primary Cancers Among Long-Term Survivors of Breast Cancer. Front Oncol. 2019;9:1426. doi:10.3389/fonc.2019.01426

36. Buumba BM, Bhardwaj S, Kaur P. A Critical Review on Recent Development of Techniques and Drug Targets in the Management of Breast Cancer. Mini Rev Med Chem. 2021;21(15):2103-2129. doi:10.2174/1389557521666210126125200

37. Pathak M, Deo SV, Dwivedi SN, Thakur B, Sreenivas V, Rath GK. Regimens of neo-adjuvant chemotherapy in the treatment of breast cancer: A systematic review \& network meta-analysis with PRISMANMA compliance. Crit Rev Oncol Hematol. 2020;153:103015. doi:10.1016/j.critrevonc.2020.103015

38. Tan W, Li Q, Chen K, Su F, Song E, Gong C. Estrogen receptor beta as a prognostic factor in breast cancer patients: A systematic review and meta-analysis. Oncotarget. 2016;7(9):10373-10385. doi:10.18632/oncotarget.7219

39. Boland MR, Ryan É J, Dunne E, Aherne TM, Bhatt NR, Lowery AJ. Meta-analysis of the impact of progesterone receptor status on oncological outcomes in oestrogen receptor-positive breast cancer. $\mathrm{Br} J$ Surg. 2020;107(1):33-43. doi:10.1002/bjs.11347

40. Guo H, Wei B, Zhang HY, et al. [HER2 expression and its prognostic implication in lymph node negative breast carcinoma: a Meta-analysis]. Zhonghua Bing Li Xue Za Zhi. 2005;34(3):140-146

41. Skjefstad K, Richardsen E, Donnem T, et al. The prognostic role of progesterone receptor expression in non-small cell lung cancer patients: Gender-related impacts and correlation with disease-specific survival. Steroids. 2015;98:29-36. doi:10.1016/j.steroids.2015.01.020

42. Hsu LH, Chu NM, Kao SH. Estrogen, Estrogen Receptor and Lung Cancer. Int J Mol Sci. 2017;18(8). doi:10.3390/ijms18081713

43. Skjefstad K, Grindstad T, Khanehkenari MR, et al. Prognostic relevance of estrogen receptor $\alpha, \beta$ and aromatase expression in nonsmall cell lung cancer. Steroids. 2016;113:5-13. doi:10.1016/j. steroids.2016.05.008 
44. Meert AP, Martin B, Paesmans M, et al. The role of HER-2/neu expression on the survival of patients with lung cancer: a systematic review of the literature. $B r \quad J$ Cancer. 2003;89(6):959-965. doi: $10.1038 /$ sj.bjc. 6601252

45. K J, F L, M L. Association between high expression of ER $\alpha$ and ER $\beta$ and non-small cell lung cancer. J Shanxi Med Univ. 2019;50 (02):181-188.

46. Clague J, Reynolds P, Sullivan-Halley J, et al. Menopausal hormone therapy does not influence lung cancer risk: results from the California Teachers Study. Cancer Epidemiol Biomarkers Prev. 2011;20(3):560-564. doi:10.1158/1055-9965.epi-10-1182
47. Pesatori AC, Carugno M, Consonni D, et al. Hormone use and risk for lung cancer: a pooled analysis from the International Lung Cancer Consortium (ILCCO). $B r \quad J$ Cancer. 2013;109(7):1954-1964. doi:10.1038/bjc.2013.506

48. Chen YY, Huang YJ, Huang HK, et al. The prognostic factors of recurrence and survival in female patients with lung adenocarcinoma and breast cancer. J Cancer Res Clin Oncol. 2020;146(5):1299-1306. doi:10.1007/s00432-020-03162-5

\section{Publish your work in this journal}

The International Journal of Women's Health is an international, peerreviewed open-access journal publishing original research, reports, editorials, reviews and commentaries on all aspects of women's healthcare including gynecology, obstetrics, and breast cancer. The manuscript management system is completely online and includes a very quick and fair peer-review system, which is all easy to use. Visit http://www.dovepress.com/testimonials.php to read real quotes from published authors. 